Article

\title{
Chinese-Style Innovation and Its International Repercussions in the New Economic Times
}

\author{
Zhifeng Shen, Ahsan Siraj, Hongbing Jiang, Yongming Zhu and Junjie Li * \\ School of Management Engineering, Zhengzhou University, Zhengzhou 450001, China; \\ shenzhifeng@zzu.edu.cn (Z.S.); ahsan.sehar4@gmail.com (A.S.); jhbymx@foxmail.com (H.J.); \\ zhuyongming@zzu.edu.cn (Y.Z.) \\ * Correspondence: lijunjie@zzu.edu.cn
}

Received: 19 January 2020; Accepted: 21 February 2020; Published: 1 March 2020

check for updates

\begin{abstract}
Innovation is the powerful headspring that makes the economy and society continue with sustainable development, and how to innovate is a current research issue all over the world. The purposes of this research are to examine Chinese-style innovations and to analyze the influence of Chinese-style innovation on the international market in the current economic times. From multiple perspectives of institutional innovation as well as scientific and technological innovation, the content, characteristics and connotation of Chinese-style innovation are comprehensively expounded and analyzed through the collection, combination and exploration of innovation, especially in Chinese-style innovation literature and interviews with relevant scholars, experts and enterprises. Then, the fit of Chinese-style innovation and characteristics of the new economic era are systematically described. Based on the exploration of international repercussions of Chinese-style innovation from both macro and micro aspects, the mechanism of Chinese-style innovation's influence on China's international market is also analyzed. In China, the underlying concept has not been well investigated before, therefore there is a gap in which to do research in this area. In accordance with the current research, a conceptual model for the new economic era, Chinese-style innovation and China's international repercussions is established. This study finds that the influence of Chinese companies in research and development has significantly improved, the all-round and multi-domain pattern of Chinese enterprises' overseas development has gradually taken shape, Chinese companies' overseas social responsibility is growing, the overseas competitiveness of Chinese companies has gradually increased, the overall strength of China's science and technology has gradually gained international recognition and its international repercussions have improved significantly.
\end{abstract}

Keywords: new economic era; Chinese-style innovation; governance model; economic development model; international repercussions; China

\section{Introduction}

Today we live in a vibrant and tempestuous global community, where innovations have been the primary chores of mankind throughout history [1]. Therefore, continuous efforts in innovations have remained imperious for improvement in quality of life and survival. Similarly, all the major innovative waves in human history like industrial, information and agricultural innovations have been made for better value creation [2].

Innovation is the source of strength for continuous development of human society and is an important scale for measuring the contribution of a country, enterprise or individual to the world. For a long period of time in the history of human innovation, it has been designed through various systems to ensure that individuals or organizations reveal and utilize natural laws with greater efficiency and then create and apply more advanced tools or methods to transform or conquer nature. However, this 
model has brought about a series of problems such as environmental degradation, resource shortages, lack of responsibility, moral decline, growth in terror and disparity between rich and poor, which is making the original intention or concept of human innovation activities gradually drift away.

Under the new economic era, given that knowledge plays an important role in the development of a society, the US future forecaster Rifkin pointed out that with rapid development and application of information technology, new energy technology and transportation technology, the new economic era has a strong feature of co-construction, co-creation and sharing [3,4]. Humanity has also begun to pursue a green, low-carbon, coordinated and shared development model [5]. Recently, China has proposed five development concepts of "innovation, coordination, green, openness, and sharing". Innovation ranks first in the "five development concepts" and is the prerequisite and guarantee for other development concepts to be implemented. As Chinese president $\mathrm{Xi}$ Jinping put it: "innovation is the first driving force for development". Without innovation, the quality and efficiency of economic transformation and structural upgrading are difficult to guarantee. Secondly, innovation is the most difficult concept among all five concepts. There are many complex problems across time and space involved in economic and social development. The other four development concepts need to be supported by theory, system, mechanism and technology.

Characteristics of innovation determine some rules that can be learned. Almost everywhere, innovation is therefore one of the hottest words in the world. Based on Chinese HowNet, it can be seen that 37 similar concepts such as subversive innovation, collaborative innovation, learning innovation, independent innovation, micro-innovation, iterative innovation and other related innovations in incomplete statistics are found [6]. Many countries and enterprises also recognize that management systems must be innovative, economic systems must be innovative, science and technology must be innovative and ideology and culture must also promote innovation. However, when innovation becomes an urgent desire for the survival and development of a country or a nation faced with the pressure of Western systems such as science, technology, culture and other innovations, then international and domestic mainstream scholars believe that China has rarely created new theoretical achievements for human beings in the past century. Since the "May 4th Movement", Chinese people have been learning from and catching up with the West, which appears to verify the correctness of this judgment. Since the reform and opening up, especially in recent years, Tu Youyou won the Nobel Prize in medicine for discovering the important contribution of artemisinin to fight against malaria during the Cultural Revolution. Liu Cixin story "The Three-Body Problem" won the 73rd Hugo Award, the world's highest award for the science fiction. In addition, China's R\&D investment reached 311 billion US dollars in 2014, exceeding the 292 billion US dollars of the $28 \mathrm{EU}$ member states for the first time. In 2017, Huawei, a Chinese enterprise, ranked first in the world with an R\&D investment of 10.363 billion Euros. Combined with China's unique political system, economic system and nearly 40 years of high-speed economic development, the phenomenon that China could not provide innovative achievements for the world in modern times is changing in the last 30 years [7].

Therefore, since 2012, scholars, consulting agencies and foreign governments have paid attention to Chinese-style innovation. Williamson and Yin found that innovation models used by many Chinese companies are challenging the traditional innovation model [8] leading to the escalation of trade war between China and the United States in 2019. Steinfeld, a professor of Chinese studies at Brown University in the United States pointed out that Chinese-style innovation is increasingly becoming an indispensable condition for any company that expects to succeed in the global market. He believed that all those involved in international business should not only see China as a market but rather as the best place to learn how to quickly commercialize ideas, how to turn ideas into products, put them into mass production and quickly occupy the market [9]. In the global effect of Chinese-style innovation, the McKinsey global institute elaborated and analyzed Chinese-style innovation in scientific research and system design in detail and pointed out the achievements, advantages and disadvantages of Chinese-style innovation as well as the enlightenment significance for other international countries and enterprises [10,11]. They also pointed out in their new work "China's Next Strategic Advantage: From 
Imitation to Innovation" that a few centuries ago, the world had to learn from China, but over the past several hundred years China has been showing patience to learn from the world and now it is time for governments and enterprises around the world to re-learn from China. Western multinationals urgently need to learn Chinese-style innovation achievements and experience because it is the most critical issue for the CEO of every multinational company. Researchers believe that Innovations are domineering for all organizations to survive and prosper in the current dynamic world [12]. They also argue that Innovations must not only for creating value for the benefits of humans whereas concentration must be given on smart future where people may enjoy best quality life.

So, what exactly is Chinese-style innovation? What are the theoretical and developmental causes of Chinese-style innovation in recent years? Chinese or Oriental philosophy, culture and values should be recognized by the world and exert more positive influence for progress of human society in the process of new economic era. But how to reach this goal? At the same time, the paper analyzes the corresponding reactions and perceptions of other economies caused by Chinese style innovation, and how the reactions and perceptions of other economies and Chinese style innovation impact traditional economic theories and international strategic theories. To this end, this paper will deeply explore the characteristics, connotations and further development of Chinese-style innovation in the new economic era and analyze how Chinese-style innovation affects other countries, overseas organizations and other individuals. It will also help to analyze the relationship amongst the New Economic Era, Chinese-style innovation and the International Repercussions of such innovations, hoping to provide valuable conclusions and reflections for follow-up scholars and relevant practitioners.

\section{Analysis of Characteristics of the "New Economic Era"}

Due to rapid development of information technology and knowledge innovation, long-term prosperity and high growth of the US economy during the Clinton administration was accompanied by low expansion and low unemployment. At the end of last century, the Organization for Economic Cooperation and Development (OECD, 1996) and the US Business Weekly (1996) first proposed the concept of "New Economic Era" for this phenomenon. Subsequently, a group of scholars and experts including 2000 Nobel Laureate in Economics Klein began to conduct in-depth analysis of the new economic era. Some scholars have pointed out that the old economy is based on enterprise products and services. The success of enterprises is mainly measured by market share. The average enterprise is concerned with the scale and efficiency. The new economy is based on information as well as information technology and enterprises take the "Internet economy" or "Internet" as the main feature. The measure of success is to reach the market time and degree of integration with information technology. So, general enterprise is concerned with technological progress. Professors of Nanjing University published an article "The Era of New Economy and Transformation of Enterprise Strategy Paradigm" in the Nankai Management Review Journal arguing that the greatest feature of the new economic era is reflected in informatization and knowledge of economic development [13]. It has a profound impact on humanization and globalization of enterprises and officially introduces the concept of new economic era into China's academic circles. According to Chen, the new economic era is marked by the knowledge economy, virtual economy and network economy [14]. However, the new economy does not only include the aforementioned economies i.e., knowledge, virtual and network economy. The true new economic era should be comprehensive combination of traditional industries and the knowledge economy, virtual economy and network economy. In 20 years since the birth of a new economic era concept, its connotation and extension have undergone profound changes. New economic era is the historical manifestation of human society in humanities, science and technology, institutional design and self-reflection in pursuit of better development of society. Some scholars believe that the new economy is based on the global economy and high technology of the knowledge economy. In terms of economy, the new economy and traditional economy have five distinct characteristics: the exchange area is wider, the new economy tends to global integration and the exchange method is different. It uses e-commerce as the foremost means of exchange; it has 
different production methods, it is mainly intensive; its growth momentum is different, it uses high technology and information as the driving force for growth; resources are shared, and it is extremely important for human beings to change production and consumption patterns.

The basic characteristics of the new economy correspond to the profound changes happening in the entire human social environment. It is a new era of economic development and the main conclusions of this era are: (1) Rapid development and wide application of information technology; Information technology has greatly improved the means and efficiency of communication in society and reduced most of the extra costs brought about by communication, production and consumption creating new industries, formats and changing the way people produce and consume. (2) Development of the traditional transportation industry; expressways and high-speed railways have been developed rapidly, air transportation has become more and more popular, speed and scale of physical transmission have been greatly improved and cost has been rapidly reduced. (3) Rapid development of new energy revolution and energy-saving technologies; the revolution in energy technologies such as shale gas, solar energy and the development of energy-saving technologies have led to a significant reduction in energy costs. (4) At the end of the Cold War; the ideological competition appeared to give way to competition in economic development strength and countries started to focus on economic construction. (5) The economy is showing a trend of global integration; it is concentrated in the globalization of market i.e., the demand market is open to any enterprise and individuals all over the world. It is possible for enterprises and individuals to seek their own markets on a global scale. (6) The globalization of resource allocation; when people choose to allocate resources, they are no longer limited to their own countries and regions. Instead, they can use their strength and sense of smell to select all kinds of resources they recognize to improve their allocation efficiency. (7) Internationalization of competition rules; almost all major countries recognize and apply their competition rules. (8) Resources are even scarcer and the contradiction between economic development and resources shortage is more prominent. (9) Awareness of green development and sustainable development has been significantly enhanced and recognized by more and more governments and people.

The arrival of the new economic era has brought new opportunities and challenges to economic development of all countries. Although the gap between rich and poor in the world is intensifying but the new economic era has indeed brought new business opportunities to enterprises in many economically underdeveloped countries. In the government work report of two sessions in 2016, Premier Li Keqiang pointed out that it is necessary to vigorously develop the new economy. This is the first time that the new economy has been written in the government work report. The connotation and extension of a new economic era have been evolving. Greenwood pointed out in his book "The Third Industrial Revolution" that current new economic era is basically equivalent to the characteristics of sharing economy [15]. The biggest features are sharing of resources and ideas of the whole society and development of green and even zero marginal cost society in the future. Through the interpretation of China's five development concepts of innovation, coordination, greenness, tolerance and sharing, overseas scholars believe it as the best interpretation of the new economic era. It is necessary to emphasize that innovation is the driving force for implementation and advancement of the concept and development of a new economic era.

\section{The Analysis of Chinese-Style Innovation Characteristics}

Innovation has always accompanied and promoted the continuous development of human society but innovation as a concept, was first proposed by Schumpeter in his book "Introduction to Economic Development" in early part of last century. Later, this concept was introduced in economics and management by scholars. Different disciplines and practices in political science, sociology, culture and art have derived different innovative concepts but they are generally divided into two aspects: i.e., institutional innovation, scientific and technological innovation. Through analyzing the results of case study, the traditional innovation paradigm at micro-enterprise level emphasizes economic feasibility, technological feasibility and advancement [16]. At the national or regional macro level, 
institutional innovation is more about ensuring economic growth and improving efficiency. McKinsey believes that micro-level scientific and technological innovation at the enterprise level includes scientific research, engineering technology, customer center and efficiency-driven innovation, while institutional innovation at the macro level includes administrative management system innovation, economic system innovation, cultural system innovation and social management system innovation [10]. Some other scholars have pointed out that Chinese-style innovation relies on the two "wheels" of scientific and technological innovation and institutional innovation to achieve an overall improvement in the country's hard power and soft power. Researchers also believe that the organizations' innovation capability increased when the new markets and new customer needs discovered through quality management [17]. They conducted their research on 133 Spanish Service Organizations and identified the combination of factors that leads towards quality in management reinforcing and innovation capability as an organization's strength. They revealed that manager's motivation and customer orientation are the main key factors to explain the presence of firm's innovation capability.

On the one hand, researchers like [18-22] believe that Quality Management emphasize more focus on customers' need and preference. They believe that the first step in process which leads to firm's innovation efforts is Knowledge. Whereas, other researchers believe that quality management as management philosophy is concerned with incremental improvements of current markets and products rather creating new values for new markets [23,24]. Experts in this field explained entrepreneurial innovation as company's behavior that is characterized by proactiveness, innovativeness, and risk-taking [25]. This reflects how companies work [26] because it is the expression of company willingness to adopt certain behavior [27].

On the other hand, some researchers have conducted analyses of entrepreneurial orientation, proactiveness and risk-taking [28]. They carried out their study between January 2018 to June 2018 by using two methods Structural Equation Modelling (PLS-SEM) and Fuzzy Set Qualitative Comparative Analysis (fsQCA). They examined the contributions and findings of six key factors. Firstly, the usage of those methods provides vigorous and consistent results. Second, validity and reliability for proactiveness, innovativeness and risk-taking are satisfactory. Third operationalizing of entrepreneur innovation using latent variables of proactiveness, innovativeness, and risk taking is satisfactory in terms of validity and reliability. Fourth, three dimensions have positive and significant influence over entrepreneurial innovation. Fifth, innovativeness is most important dimension of entrepreneur innovation and orientation. Sixth, innovativeness is necessary and more than sufficient condition for entrepreneur innovation and orientation. In a study, researchers examine the impact of export and technologies on economic performance of the emerging countries of Asia by using the Generalized Method Moments (GMM) models between the period 2000-2016 [29]. In their study, they recommend policymakers to make attractive policies which can enhance the advancement of trade and technology to maintain the sustained economic growth. This can also fasten the internationalization process and will enable them to compete the efficiently in global markets in terms of quality of exports and standardization. He et al. [30] conducted a study using panel data model on Chinese listed companies and by taking data from 2012 to 2017. The results of their study suggest that brand equity will play a vital and important role in the future growth of China whereas proper attention should be devoted to it in terms of policy and regulation. Urbano et al. conducted their research to determine the relationship of entrepreneurial activities and role of institution in combined output for countries which are in developing phase [31]. They used the sample of 14 countries having 78 observations and by taking the data between 2004 to 2012. Their findings reveal the causal chin between institutions and opportunity entrepreneurship which is also linked with the economic growth of emerging economies.

But what is Chinese-style innovation and is there any country-specific innovation? This is the first reaction to people's talk about Chinese-style innovation. Researchers believe that Chinese-style innovation has been discussed for a long time but it has just taken off in recent years [32]. The biggest driving force comes from the combination of mature manufacturing capacity, large-scale local market and rapidly rising scientific research level. This synergy effect has only appeared twice, that is, 
the British Empire in the industrial revolution era and American business empire after World War II. The 2015 OECD Science, Technology and Industry Outlook report stated that China's R\&D investment in 2014 reached US\$311 billion surpassing R\&D investment of US\$292 billion in 28 EU member states for the first time. This means that the era of China's replication of European and American technology is finally over. As early as 2012, China's investment in research and development was almost same as of the European Union. In that year, China invested 257 billion US dollars and the EU 282 billion US dollars. Chinese economy is forming a similar "intensive R\&D" trend with Europe and the proportion of R\&D investment in GDP is close to that of industrialized countries. De Marco et al. conducted their exploratory study to examine the SME's engagement in implementation of Open Innovation [33]. They test their methodology by taking European SMEs operating in digital sector as sample. They find that the SME's which are being awarded with grants are less engaged in implementation of open innovation whereas on the other side, SMEs which are having no grants and funds are working contrary to this.

According to the latest 2016 fortune global 500 lists, there are 110 Chinese companies on the list, second only to 128 in the United States. This is a reflection of China's economic development achievements and a vivid portrayal of Chinese-style innovation. The Chinese-style political and economic system innovation has also played an important role. The Chinese-style innovation ecosystem will become the mainstay of global innovation. The innovation advantage will gradually shift to the forefront of global industrial chain and challenge the unknown areas of humanity, such as Guizhou Fast (a super-point telescope), super-computer, aerospace technology, high-speed railway construction and related equipment manufacturing etc. The rapid iteration of the internet and traditional industries has shaped the Chinese culture such as mass innovation, entrepreneurship and maker culture. This indicates that China has entered into a new era of promoting innovation through the trinity of policy system, financial system and industrial ecology and initially formed an ecological circle of innovations and incentives. Many examples also prove that China has its own innovations, methods and characteristics that are different from other countries. It is no accident that companies or products such as WeChat, Taobao and Xiaomi have strong Chinese-style characteristics of innovation. In a speech entitled "innovation with Chinese characteristics" in Silicon Valley, Li, the founder of Innovation Works, said that the innovation of Chinese technology companies stems from the following aspects. First, it is diligent; he showed Tencent headquarters building photos at 2:00 AM; the office is still brightly lit and downstairs taxi drivers are waiting for the return of the working staff. The second is fast execution, which can be illustrated by the example of a 30-story luxury hotel completed within 15 days. The third is resilience and concentration; this is the product of China's employment, life and competitive pressure during the social transition period. Therefore, in recent years, many British and American scholars are optimistic about the future of China's economy and believe that China is creating new innovation models and calling on the West to abandon stereotypes and learn from China.

Although Chinese-style innovation was born in the new economic era, it has a close relationship with China's market, development concept, culture, philosophy and moral atmosphere. It has its unique characteristics. This paper combines practical observations and literature review as follows.

\subsection{Chinese-Style Innovation Advocates Simplicity}

Because China has a large population and limited resources, it is the core mission of Chinese-style innovation to create more value with limited resources. Some researchers pointed out that in the era of prevalence of instrumental rationality and technologicalism advocated by developed societies and large multinational corporations, the "small", "simple" and "concise" Chinese-style innovations reflect more the value orientation of Chinese traditional philosophical wisdom [34,35]. The Chinese-style innovation paradigm contains traditional and simple philosophical thoughts. We will find that although Confucianism, Taoism and Law have different interpretations of simplicity, their basic philosophy and values are the same which can be concluded as the treasure of resources and the importance of people's livelihood and security and thus the wisdom of green and sustainable development. This kind of innovation must respect the laws of nature and social development and require being pragmatic. 
While satisfying the increase of social value and the happiness of people's livelihood, we must also advocate frugality and simplicity and fully reflect China's traditional culture and philosophy.

\subsection{Chinese-Style Innovation Focuses on Speed}

Traditional science and technology and social system innovations often have large investments, long periods of time and bring about social turbulence. The pragmatic and fast-paced concept of "only fast and not broken" is integrated into the blood of Chinese-style innovation, which is related to the politicians of China and the starting model of enterprises. Williamson and other scholars believe that Chinese companies pay attention to "accelerating innovation", that is, looking for new methods, speeding up product upgrading, shortening the lead time of a certain product in the market, minimizing the cost of introducing new products into the market, shortening innovative products, and the scale of investment in production and rapid opening of the mainstream market cycle. This kind of Chinese-style accelerated innovation is the most powerful proof of innovation strength of Chinese enterprises. Williamson pointed out that "Chinese-style innovation" will quickly bring design products to market and quickly occupy the market in a record-time. This innovative model can effectively reduce costs, respond to market demands in a timely manner and respond flexibly to challenges leaving the "fast followers" behind. Researchers also said that Chinese companies operate at "China speed", foreign companies need three months and Chinese companies will even compress to three days [36].

\subsection{Chinese-Style Innovation Focuses on Low Cost}

The cost of starting a business in China is relatively low and a good team can be built at a very low cost. Over the past 30 years, many multinational companies have chosen China as a base for low-cost rapid innovation and effects of Chinese-style innovation will be felt everywhere in the world. Overall, this effect will have a disruptive impact which will drive large-scale, flexible and agile innovations that address the unmet needs of emerging markets, create new products and services for advanced economies and global consumers will be able to enjoy more affordable products, which is also closely related to the weakness of Chinese companies and the aim of targeting the middle and low-end market of pyramid.

\subsection{Chinese-Style Innovation Has a Strong Political Colour}

Researchers believe that China's central and local governments attach great importance to innovation and their policies are significantly stronger than other countries [11]. They create collaborative innovation centers, technology parks, and innovation incubators to support businesses, research institutes and individual innovations by providing initiatives, policies and regulations and funding for research. Lampton pointed out that in complex civil society and the international system, it is extremely difficult to decide what to do [37]. Once the decision is made and the policy intentions need to be completed, the difficulties can be imagined because Chinese government has strong policy decisions and executive power to ensure that the goals are implemented. In many Western countries, when policies pass through layers of government agencies and civic organizations, their intentions and effects will be greatly reduced and they are reduced layer by layer. Some scholars have associated these difficulties with a concept called "smart power" which means the ability to define goals and achieve policies in the most efficient way. The Chinese government is very smart in this perspective. It positions itself as an innovation-driven mechanism and institution rather than a "nanny" to innovation. Therefore, the Chinese government also fully respects the market-based survival of the fittest.

Some countries, such as the United States, do not recognize China's market economy status internally. Due to historical problems, although China has more state-owned enterprises, China believes that its market economy status should be recognized by other countries. No matter what, Chinese style innovation does have a relatively more political color. Maybe this is not the same as the 
glorious history of China before 1840 and the century of 1840-1945. Fortunately, the history may also be related to China's special political system.

\subsection{Chinese-Style Innovation Pays More Attention to "1 to N"}

For China, there are two roads to innovation, one from 0 to 1 and the other from 1 to N. From 0 to 1 is the beginning; the original innovation, the creative innovation, the effect of this innovation may be explosive but there is also the "creative destruction" that Schumpeter said risk management and innovation are extremely demanding. The study pointed out that the most representative of this innovation road in the world is the United States, which is mostly a winner-take-all mode and causes fatal damage to traditional industries [38]. From 1 to $\mathrm{N}$ is from 1 to more, from ownership to proficiency, improve ceaselessly, the pursuit of the ultimate, the risk is low and there are certain rules to follow.

It should be emphasized that in a certain innovation field, Chinese style innovation is different from other countries' innovation models by realizing "from 1 to $\mathrm{N}$ " and then using "from 1 to $\mathrm{N}$ " to encircle "from 0 to 1 ". Once the developed countries have this "from 0 to 1 " capacity, the developed countries do not pay much attention to "from 1 to $\mathrm{N}$ " capacity building. China combines the two capacities well.

\subsection{Follow the Credo of "Learning from Failure"}

Researchers believe that Chinese companies and governments all follow the credo of "learning from failure" [11]. Institutional innovation is the first to try, touch the stones and cross the river, constantly try and make mistakes and constantly optimize and improve. It may not be perfect for a company to launch a new product. Based on customer feedback, the improved iterative product will appear soon and then continues to improve. This approach to innovation recognizes the innovation gene that "completion is more important than perfection." Researchers believe that it is related to the Chinese company's tendency to provide products that are not the highest quality but more "applicability" [32]. Western companies are too concerned about the quality and reputation of brand and cannot flexibly reduce the quality of their products. So quickly, they are defeated by its Chinese counterparts with lower quality but lower prices and faster iteration speed mostly due to the continuous trial-and-error spirit of Chinese-style innovation.

\subsection{Chinese-Style Innovation Focuses on Collaborative Sharing}

This kind of innovation has the characteristics of open innovation as referred by [39]. China attaches importance to collectivism and Chinese government's involvement in innovations of enterprises, research institutes and other individuals. Therefore, some scholars believe that Chinese-style innovation can best reflect the characteristics of collaborative, shared and open innovation. For example, the results of early Chinese artificial insulin, artemisinin, research and development of super-computers in the past are the results of collaborative and shared innovation. Collaborative sharing innovation is a more complex organization of innovation. The key is to form a network innovation model with multi-subjects as the core elements of universities, enterprises and research institutions with government, financial institutions, intermediary organizations, innovation platforms, non-profit organizations as auxiliary factors. Through the deep cooperation and resource integration between the knowledge creation subject and the technology innovation subject, more original innovations are generated. This kind of feature is conducive to the realization of an open, cooperative and shared innovation model in the context of the globalization of science and technology economy. This is more important to achieve a deep collaboration and open innovation in different organizations and to accelerate the integration and diffusion of technology in different areas, industries and innovation.

Different from the previous national innovation model, Chinese style innovation is more willing to share this technology and related products with other countries and enterprises, such as Chinese enterprises are more willing to share $5 \mathrm{~g}$ technology and products, high-speed rail technology and 
products, etc. Although Chinese style innovation attaches great importance to the protection of intellectual property rights, it is also a slight difference between China's treatment of innovation protection and other innovation models.

\subsection{Chinese-Style Innovation Focuses on Middle And Low End of Pyramid Market}

The widespread use of this model by Chinese companies in process of product innovation and service model innovation has also enabled a group of Chinese companies such as Xiaomi to succeed in the Chinese market as well as overseas competitors. Since the middle and low-end market in the pyramid is large, therefore, the developed solutions must be able to replicate and migrate between different countries, cultures and languages. The design of innovative solutions must be easy to adjust in the similar middle and low-end markets. Besides, innovative products and services can be consumed on a large scale in the local market to save cost and reflect the advantages of this innovative model which is also a key point to achieve economies of scale. In addition, researcher believes that the problems faced by consumers at the middle and lower end of the pyramid cannot be solved by original technologies and most of them can adopt extended price-performance solutions that require more advanced and emerging technologies to be creatively combined with existing and rapidly evolving infrastructure [40]. However, China's enterprises and market environment are very compatible with this innovative model and have begun to become a distinctive feature of Chinese-style innovation.

Some scholars believe that the reason for birth of Chinese-style innovation is emergence of "internal and external troubles" such as resource crisis, environmental degradation, decline of economic growth, gradual improvement of labor costs and development of internationalization in the depth direction. The transition from "Made in China" to "Create in China" is becoming more and more imperative. In the new economic era, especially the transformation depends on innovations in systems, science and technology and China will gradually change from "followers" to "innovators". In terms of institutional innovation, although foreign development provides experience in China's social governance, economic restructuring, transformation, formulation of industrial support policy innovations, China's national conditions and especially political and economic systems are very different from those of Western developed countries. In the transition period of China's society, there is an urgent need for a large number of supporting macro and micro mechanism innovations. Therefore, we have great obstacles and difficulties in innovation at the institutional level. Some researchers found that difficulty of introducing advanced technology from foreign countries is increasing and the pressure of scientific and technological innovation is enormous [41]. Whereas other researcher believes that although enterprise-level innovation in China has achieved a lot of milestones but from the perspective of most enterprises, there are four shortcomings in Chinese-style innovation at present; the developmental innovation consciousness is "shallow", the R\&D investment is "low", the innovative talent is "lacking" and the shared R\&D platform is "less" [42]. In a similar kind of study, researcher calculated a conflict index among stakeholders' groups [43]. Their findings show that development and conservation goals are most preferred to be considered in planning of these areas. Furthermore, they also find the most serious disagreement between scientists and farmers and between government and farmers about the wildlife conservation.

It should be emphasized that Chinese style innovation has seized the middle and low-end market of the pyramid, gradually "encircled" the high-end market from the middle and low-end market, and finally occupied the high-end market, which is different from the previous national innovation mode. When the developed economies occupy the high-end market, they gradually withdraw from the low-end market. Chinese style innovation does not follow this rule.

\section{Analysis of International Repercussions on Chinese-Style Innovation}

The main research on international repercussions of a country in the world is roughly divided into macro and micro levels. The former includes scientific and technological, political, economic, military and cultural influence of the national macro level, such as Hu published relevant articles on "Looking 
at the Perspective" to analyze international repercussions of China's macro level [44]. The latter is the micro level of the enterprise including the influence of corporate technology research and development, corporate management capabilities, corporate capital reserves and financing capabilities. Articles on China's international repercussions are often seen in newspapers but there are not many articles on academically in-depth study of China's international repercussions. Most of them are talking about the general level of China's economy, military strength, the number of participating international organizations and the unique long history and culture at the macro level. In fact, the enterprise level in new economic era has more important role in enhancing the overall overseas influence of a country. International repercussions of China's macro level have been rapidly improved in the past 30 years. Scholars at home and abroad generally believe that it is inseparable from China's institutional innovation, acquisition and innovation models of introduction, digestion and resorption. The main research conclusions are as follows.

\subsection{Chinese Style Innovation Has Profoundly Changed the Mode and Structure of International Trade}

International trade is roughly divided into four main parts: primary products, manufactured goods, service trade and technology trade. Most of the trade patterns of one country start from the primary products, gradually transition to the industrial manufactured goods, service trade and technology trade by improving its own innovation ability, and then deeply integrated into the global industrial chain and value chain, thus forming the classic theory of international trade division: "the flying-geese model". However, Chinese style innovation does not follow this trade model, which includes four aspects: primary products, industrial manufactured goods, service trade and technology trade. While improving the trade level, many industries in china have not retreated from the low-level trade mode.

Similarly, Chinese style innovation challenges the "smile curve" formed by the division of labor in international trade, i.e., developed economies engage in international trade activities related to R \& D and product services. This part of the added value is higher, while developing countries are responsible for the production of products, and this part of the added value is lower. However, while doing well in R \& D and service, Chinese style innovation did not withdraw from the product processing area and formed an international brand made in China. This phenomenon has led the US government to advocate "industrial return" or "reindustrialization", block China's 5G network development efforts, and launch a "trade war" that will last for a long time, which will deeply impact the international trade mode and trade structure.

\subsection{Chinese Style Innovation Impacts Many Classical Economic Theories}

According to the characteristics of Chinese style innovation and the analysis in Section 4.1, Chinese style innovation challenges many international strategies and theories of international trade, including comparative advantage theory, competitive advantage theory, institutional theory and resource-based view. Whether or not the trade war between China and the United States and the "Reindustrialization" of the United States conform to the advantages and rational thinking of the United States, but this behavior does conflict with the theory of comparative advantage and the theory of competitive advantage, which is more or less related to the characteristics of Chinese style innovation from " 1 to N" surrounded by " 0 to 1 ", and from the low-end market "surrounded" high-end market ". In addition, the complete market economy system environment is more suitable for the current innovation system and internationalization behavior, especially for the system environment of developed countries. It seems that China's system environment does not fully meet this market situation, or is called "Chinese characteristics", but this environment shows greater innovation and internationalization advantages, which is also conducive to the existing system theory and resource-based view, the validity of those theory is challenged. 


\subsection{China's Governance Model Has Received Widespread Attention}

Since founding of People's Republic of China especially since the reform and opening up, China's comprehensive national strength has been greatly enhanced by drawing on innovation, introducing, digesting and re-innovating, rapidly iterating micro-innovation and low-cost innovation. Moreover, domestic and foreign scholars believe that China is currently at the center of world economic, political and cultural arena and has become the engine of world economic growth, trade growth, investment growth, invention patent applications and the largest increase in applications. Moreover, it is also the largest source of international tourists, consumption expenditures and the largest source of overseas students. Chinese-style innovation plays a decisive role in this process, especially the innovation features of its speed, efficiency, applicability, trial and error. For example, China's rural progressive reform, the pioneering and piloting mode of reform and opening up, the concept of socialist modernization with Chinese characteristics advancing with the times have played an important role in governance model of the country and have received more support and recognition from state. At present, more than $90 \%$ of countries in the world regard China as focus of their diplomatic relations. China is also a sponsoring country or an important constituent country of important international and regional organizations in the world. China has become a country where Chinese leaders have visited abroad or leaders of other countries have visited China the most. The country's soft power in the international arena has also been comprehensively upgraded. Some scholars and politicians even put forward the G2 development model featuring comprehensive dialogue between China and the United States avoiding conflicts and benign competition. These all are collective signs that China's governance and Chinese-style innovation have received widespread international attention.

\subsection{China's Economic Development Model Has Been Widely Recognized}

According to the exchange rate method, China's total GDP has increased from $9.2 \%$ in 2010 to $14.4 \%$ in 2015 . It is estimated that by 2020 , regardless of the exchange rate law or purchasing power parity method, China's GDP will increase to around $20 \%$ of the world. The share of China's imports and exports increased from $9.65 \%$ in 2010 to $11.34 \%$ in 2014 . The proportion of China's exports of goods increased from $10.4 \%$ in 2010 to $13.2 \%$ in 2015 , the average annual growth of service trade exceeded $13.6 \%$. At present, service trade ranks second in the world and it has become the world's largest trade body as a whole. Goldman Sachs senior consultant Joshua Cooper pointed out in the "Beijing Consensus" that China's economic development model reflects the advantages of China's economic system innovation and even believes that China's economic development and innovation experience has "universal value." Scholars believe that innovation is the engine of China's economic development and the means of continuous improvement.

So far, institutional innovation and technological innovation have brought ultra-rapid changes to some departments enabling China to develop at a pace sufficient to solve the problems brought about by the reform. The rapid changes brought about by Chinese-style innovation, problems caused by such changes have not yet appeared and new changes have taken place. In physics terms, it is the use of innovation to reduce the friction loss in reform.

\subsection{The Overall Strength of China's Science and Technology Has Gradually Gained International Recognition and Its International Repercussions Improved Significantly}

Scientific and technological strength refers to the sum of a country's scientific innovation capability, technological innovation capability, scientific and technological input capability and ability of the whole society to use latest technological capabilities. Four specific quantitative indicators are: number of international scientific papers published, number of domestic invention patent applications, total research and test expenditures and total number of Internet users. The research results show that China's science and technology will go up a big step in every five-year plan. In 2000, China's scientific and technological strength accounted for 3.85\% of the world whereas the United States was 7.01 times that of China. In 2010, China's share of the world increased to $16.00 \%$ and the share of the United States 
shrank to 1.31 times that of China. In 2014, China reached $23.49 \%$ exceeding $19.30 \%$ of the United States and equivalent to 1.22 times the United States. For example, in November 2015, the White Paper on "Chinese Science in Transformation" published by Nature Publishing Group pointed out that China is already the second largest contributor to the Global Nature Index showing a high level of scientific research strength and apparently in absolute quantity. China's contribution to global high-cited papers is second only to the United States.

\subsection{Promote Chinese Culture to Return to the Mainstream of World}

China is the only ancient civilization in the world with an unbroken history and profound cultural heritage. However, in the past 200 years, Chinese culture has faded from the center of the world stage. For nearly 30 years, Chinese government has attached great importance to the innovation of content, methods and ideas in the process of cultural innovation and foreign cultural exchanges. For example, Confucius Institutes, Chinese Medicine, Chinese Kung Fu, Chinese Food, Chinese Language and Chinese Studies outside the China have been promoted and recognized in many overseas countries. This is an important manifestation of the increase of Chinese culture in international repercussions and this is inseparable from the charm of Chinese culture, concept of communication, the means and innovation of cooperation methods.

Although there are still many unfavorable factors restricting the overseas influence of Chinese enterprises such as international, government and enterprise factors. It is an indisputable fact that the overseas influence of Chinese enterprises has been greatly improved with improvement of China's R\&D and innovation capabilities. McKinsey's analysis report pointed out that China's overseas competitiveness has gradually increased and the international repercussions of Chinese enterprises are as follows [10].

\subsubsection{The Overseas Competitiveness of Chinese Companies Has Gradually Increased}

Since the international discourse power has continuously raised financial crisis, the strength of the major western countries has been hit hard. The growing strength of Chinese companies in emerging economies has also aroused global attention. Even with the existence of financial crisis, they have begun to participate in development of international technical standards and trading rules of the industry; especially international financial crisis has highlighted the international repercussions of Chinese companies more and more. Western companies actively cooperate with Chinese enterprises in international cooperation and the corresponding discourse rights of Chinese enterprises are also increasing. At present, China has a number of internationally influential enterprises.

\subsubsection{Chinese Companies' Overseas Social Responsibility Is Growing}

The overseas development of state-owned enterprises has become increasingly effective in alleviating the contradiction of domestic resource shortages, promoting industrial restructuring, expanding exports, increasing employment and enhancing foreign friendly relations and cooperation. However, in recent years, Chinese companies have more to abide by the "win-win principle" and actively fulfill the necessary social responsibilities in local area after making profits. In response to the National One Belt and One Road Strategy and International Capacity Cooperation Program, Chinese companies such as China Communications Construction, China Nonferrous Metals, Sinoma Group and other companies pay attention to cultivating local talents, fulfilling international social responsibilities and intending to promote the development of local industrial systems as well as social and economic development. It has made positive contributions to local infrastructure construction, education and environmental sanitation. The influence of Chinese enterprises in Africa, Southeast Asia and Central Asia has been rapidly improved as compared to Western enterprises. 
4.6.3. The All-Round and Multi-Domain Pattern of Chinese Enterprises' Overseas Development Has Gradually Taken Shape

The all-round and multi-domain pattern of Chinese enterprises' overseas development has gradually taken shape. The main performance is as follows: the scale of overseas investment by Chinese companies is increasing and the field of corporate investment is gradually broadening. China's "going out" strategy has basically formed a diversified strategic pattern of "Asia-based, developing Africa, expanding Europe, America, Latin America and South Pacific." Chinese companies are improving local people's livelihood and promoting local economic development including agriculture, manufacturing, energy, transportation, telecommunications and other infrastructure and basic industries that can help these countries improve their economic "hematopoietic" functions and also increase cooperation in resource areas such as oil and gas and solid minerals development. The influence of Chinese companies is increasing. For example, the increasing scale of overseas investment by Chinese companies and the continuous expansion of corporate investment are the best evidence.

4.6.4. The Influence of Chinese Companies in Research and Development Has Been Significantly Improved

McKinsey Company pointed out in the "Global Effect of Chinese-style innovation" that Chinese companies ranked first in international market for dozens of products in the six industries of Efficiency-Driven innovation. McKinsey Company believes that over the past 30 years, China's economic growth has relied mainly on the "Innovation Sponge" model, which is to catch up with leading countries by absorbing and improving internationally advanced technologies, best practices and knowledge [10]. Chinese companies are catching up in the field of scientific research in a unique way. The Chinese government has long been committed to increasing R\&D investment, cultivating scientific research talents and encouraging patent applications but China has not yet achieved a leading position in scientific research innovation. Today, Chinese companies are driving innovation in a unique way in research-using China's low-cost and sufficient research talent to accelerate experimentation and discovery processes and achieve rapid development of research and innovation.

\section{Conclusions}

This paper first analyses deep-seated reasons for the arrival of new economic era, its main features and the judgment and understanding of China's characteristics of the new economic era from an international perspective. Secondly, this paper combines the current situation of China's institutional innovation and scientific and technological innovation with its international repercussions. It also combines relevant literature to sort out and analyze the main characteristics of the concept of Chinese-style innovation. Finally, on the basis of above research, overseas influence of Chinese-style innovation has been comprehensively explored from the macro and micro levels. This research also shows that the concept of Chinese-style innovation is a concept put forward by some scholars and consulting agencies in recent years. However, the achievements of Chinese-style innovation show that it has existed for a long time and Chinese-style innovation is the best adaptation or response to new economic era. Chinese-style innovation is embedded in the characteristics of globalization in new economic era. There are many ideas and cooperation methods that are worth learning from other developing countries and even developed countries. Therefore, the influence of Chinese-style innovation will inevitably be not limited to domestic level. The relationship between characteristics of the new economic era, Chinese-style innovation and its overseas influence is shown in Figure 1. 


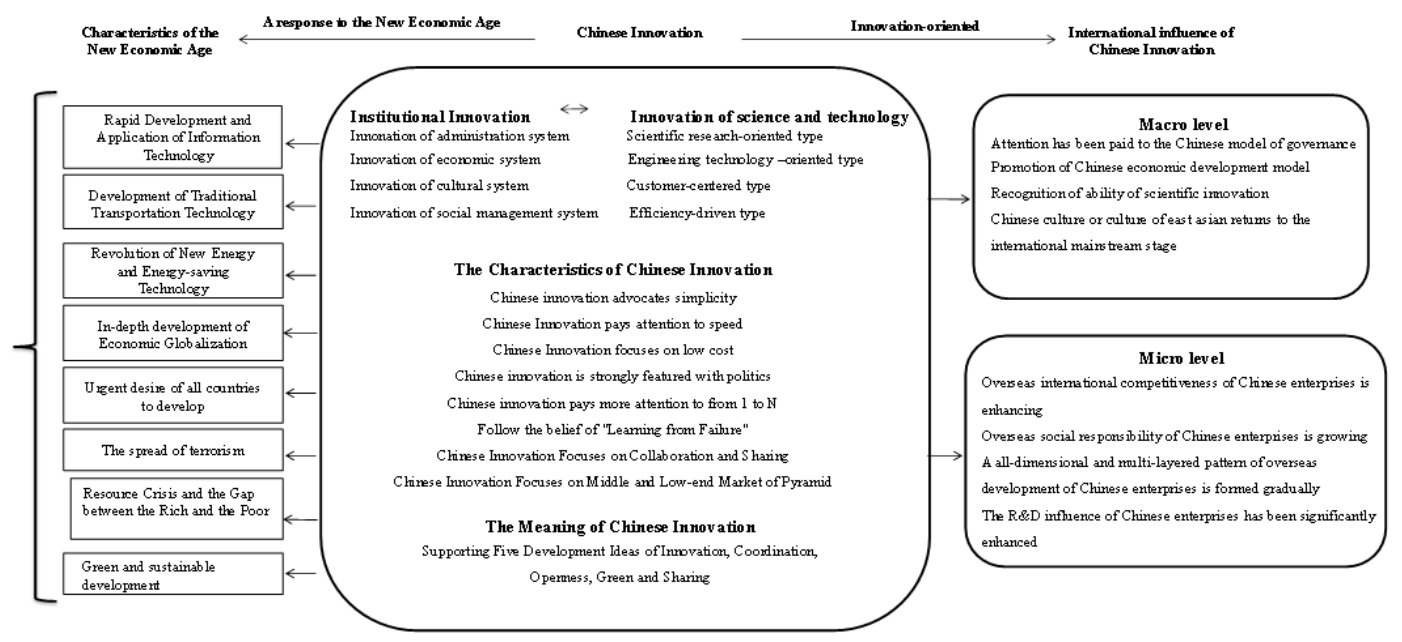

Figure 1. The new economic age, Chinese-style innovation and its international repercussions model.

The only unrealized goal of China's innovative country construction is to control external dependence of technology below $20 \%-30 \%$, which is also an important indicator of the "13th Five-Year Plan" for technological innovation. In view of China's national conditions, Chinese-style innovation should attach importance to original innovation and independent innovation on the basis of previous systems and scientific and technological innovation advantages and characteristics. On the one hand, a group of scholars such as researchers [16] pointed out that China's innovation strategy must be adjusted and reconstructed, with the focus on supporting the innovation of small and medium-sized enterprises, especially the establishment of entrepreneurship and innovation platform for small and medium-sized enterprises. At the same time, let the people participate in creative design and technology development, let investors participate in the establishment and development of new enterprises. As a result, innovation subjects with different innovation scales and goals can form a sound innovation ecosystem and formulate an innovation and investment aggregation mechanism that is suitable for China's national conditions. These will promote a high degree of integration of creativity, innovation, entrepreneurship and venture capital; producing more small and medium-sized enterprises with original ability which is a sign of innovative strength of an innovative country and the basis for further development. On the other hand, it strengthens the innovation of national basic scientific research, scientific and technological frontiers and combines the frontier issues of the discipline with the major theoretical and practical issues in economic and social development. It enhances the basic research capabilities of public scientific and technological characteristics, industrial common technology research and development capabilities and engineering technology research capabilities. China's existing research institutions have small scale, redundant construction and corporate $R \& D$ functions that are equally weak. They cannot provide effective technical support for enterprises and on the contrary, some even use meaningless precious scientific and technological resources. In process of carrying out the reform of future science and technology system, it is necessary to create an industrial research institute that can support the development of various industries and provide a stable guarantee for the major research of industrial technology. On this basis, resources should be concentrated in universities and research institutes to build a number of large-scale national laboratories with world-leading levels, engaging in basic, long-term and forward-looking, public welfare basic research and frontier work of science and technology.

Chinese-style innovation as a new concept; the current research focuses on qualitative research and follow-up studies should conduct case studies and quantitative studies to further explore the characteristics, role, value of Chinese-style innovation and its impact on the overseas strategic deployment of China's Belt and Road and international capacity cooperation programs. It also focuses on the impact of Chinese-style innovation on internationalization strategy and performance of 
Chinese enterprises. The results of this paper show the positive role and international repercussions of Chinese-style innovation. However, there are still many shortcomings in Chinese-style innovation, which should attract the attention of academic and practical circles such as the emergence of waste oil, melamine and other "dangerous innovation" behavior. There is also the negligence of environment and resource crisis by the speed and efficiency of Chinese-style innovation such as the large area of haze in North China and problems caused by innovative short-sightedness i.e., water pollution and soil pollution. Finally, the negative international repercussions brought by Chinese-style innovation such as the China threat theory caused by overseas and intellectual property rights brought by "cottage", academics and practitioners should explore ways and measures to reduce this negative impact.

Lastly, for Chinese style innovation to effectuate sustainability, as aforementioned, the results of this paper show the positive role of Chinese-style innovation in international repercussions. So, it can be said that this will create and integrate innovative business strategies, products and services which will accelerate a positive social change. It will also preserve and protect the environmental integrity while enhancing the sustainability and businesses performances in overseas strategic deployment of China's Belt and Road and international capacity cooperation programs.

Author Contributions: Conceptualization, Z.S. and H.J.; formal analysis and writing—review and editing, J.L.; data curation and writing - original draft preparation, A.S.; supervision, Y.Z. All authors have read and agreed to the published version of the manuscript.

Funding: This research was funded by National Natural Science Foundation Project, grant number G020803, Henan Philosophy and Social Science Planning Project, grant number 2018BJJ049, Soft Science Research Project of Henan Province, grant number 172400410216 and Humanities and Social Sciences Project of Henan Education Department, grant number 2019-ZZJH-069.

Conflicts of Interest: The authors declare no conflict of interest.

\section{References}

1. Lee, S. The age of quality innovation. Int. J. Qual. Innov. 2015, 1, 1. [CrossRef]

2. Lee, S.M.; Olson, D.; Trimi, S. Co-innovation: Convergenomics, collabo-ration, and co-creation for organizational values. Manag. Decis. 2012, 50, 817-831. [CrossRef]

3. Rifkin, J. How developing nations can leapfrog developed countries with the sharing economy. Huffington Post. 2015. Available online: http://www.huffingtonpost.com/jeremy-rifkin/developing-nations-sharingeconomy_b_8419960.html (accessed on 20 February 2020).

4. Rifkin, J. The Zero Marginal Cost Society: The Internet of Things, the Collaborative Commons, and the Eclipse of Capitalism; St. Martin's Press: New York, NY, USA, 2014.

5. Ehret, M.; Wirtz, J. Unlocking Value from Machines: Business Models and the Industrial Internet of Things. J. Mark. Manag. 2017, 33, 111-130. [CrossRef]

6. Wang, J.; Li, H. The Characteristic and Path of the Innovation-Driven Strategy: The Experience of Tianjin under the Background of New Technology Revolution. Theory Mod. 2015, 27, 27-34.

7. Lecossier, A.; Pallot, M.; Crubleau, P.; Richir, S. Construction of an instrument to evaluate the User eXperience of a group of co-creators in the upstream innovation process. Int. J. Serv. Oper. Inform. 2019, 10, 17-42. [CrossRef]

8. Williamson, P.J.; Yin, E. Accelerated innovation: The new challenge from China. MIT Sloan Manag. Rev. 2014, $55,27$.

9. Steinfeld, E.S. Emerging Energy Technology Innovation and Development Capabilities in China; Brown University: Providence, RI, USA, 2017.

10. Mckinsey Global Institute. The Global Impact of Chinese Innovation. 2015. Available online: https: //www.mckinsey.com.cn/wp-content/uploads/2016/03/China-innovation_CN_full-report.pdf (accessed on 23 October 2019).

11. Yip, G.S.; McKern, B. China's Next Strategic Advantage: From Imitation to Innovation; MIT Press: Cambridge, MA, USA, 2016.

12. Lee, S.M.; Trimi, S. Innovation for creating a smart future. J. Innov. Knowl. 2018, 3, 1-8. [CrossRef] 
13. Zhou, S.; Zhou, J. The Era of New Economy and Transformation of Enterprise Strategy Paradigm. Nankai Bus. Rev. 2002, 5, 29-32.

14. Chen, S. Interpreting the new economy. Fuzhou Univ. J. Philos. Soc. Sci. Edtion 2001, 15, 5-14.

15. Greenwood, J. The Third Industrial Revolution: Technology, Productivity, and Income Inequality; The AEI Press Publisher for the American Enterprise Institute: Washington, DC, USA, 1997.

16. Chen, J.; Zhao, X.; Wang, Y. A new measurement of intellectual capital and its impact on innovation performance in an open innovation paradigm. IJTM 2015, 67, 1-25. [CrossRef]

17. González-Cruz, T.F.; Roig-Tierno, N.; Botella-Carrubí, D. Quality management as a driver of innovation in the service industry. Serv. Bus. 2018, 12, 505-524.

18. Prajogo, D.I.; Sohal, A.S. TQM and innovation: A literature review and research framework. Technovation 2001, 21, 539-558. [CrossRef]

19. Prajogo, D.I.; Sohal, A.S. The relationship between TQM practices, quality performance, and innovation performance: An empirical examination. Int. J. Qual. Reliab. Manag. 2003, 20, 901-918. [CrossRef]

20. Prajogo, D.I.; Sohal, A.S. The multidimensionality of TQM practices in determining quality and innovation performance-An empirical examination. Technovation 2004, 24, 443-453. [CrossRef]

21. Prajogo, D.I.; Sohal, A.S. The integration of TQM and technology/R\&D management in determining quality and innovation performance. Omega 2006, 34, 296-312.

22. Hoang, D.T.; Igel, B.; Laosirihongthong, T. The impact of total quality management on innovation: Findings from a developing country. Int. J. Qual. Reliab. Manag. 2006, 23, 1092-1117. [CrossRef]

23. Slater, S.F.; Narver, J.C. Customer-led and market-oriented: let's not confuse the two. Strateg. Manag. J. 1998, 19, 1001-1006. [CrossRef]

24. Hoang, D.T.; Igel, B.; Laosirihongthong, T. Total quality management (TQM) strategy and organisational characteristics: Evidence from a recent WTO member. Total Qual. Manag. 2010, 21, 931-951. [CrossRef]

25. Miller, D. The correlates of entrepreneurship in three types of firms. Manag. Sci. 1983, 29, 770-791. [CrossRef]

26. Lumpkin, G.T.; Dess, G.G. Clarifying the entrepreneurial orientation construct and linking it to performance. Acad. Manag. Rev. 1996, 21, 135-172. [CrossRef]

27. Wiklund, J. The sustainability of the entrepreneurial orientation-Performance relationship. Entrep. Theory Pract. 1999, 24, 37-48. [CrossRef]

28. Ibarra-Cisneros, M.; Hernandez-Perlines, F. Entrepreneurial orientation, absorptive capacity and business performance in SMEs. Meas. Bus. Excell. 2019. [CrossRef]

29. Sultanuzzaman, M.R.; Fan, H.; Mohamued, E.A.; Hossain, M.I.; Islam, M.A. Effects of export and technology on economic growth: Selected emerging Asian economies. Econ. Res. Ekon. Istraživanja 2019, 32, 2515-2531. [CrossRef]

30. He, Q.; Guaita-Martínez, J.M.; Botella-Carrubi, D. How brand equity affects firm productivity: The role of R\&D and human capital. Econ. Res. Ekon. Istraživanja 2019, 1-17. [CrossRef]

31. Urbano, D.; Audretsch, D.; Aparicio, S.; Noguera, M. Does entrepreneurial activity matter for economic growth in developing countries? The role of the institutional environment. Int. Entrep. Manag. J. 2019, 15, 1-35. [CrossRef]

32. George, G.; Lin, Y. Analytics, innovation, and organizational adaptation. Innovation 2017, 19, 16-22. [CrossRef]

33. De Marco, C.E.; Martelli, I.; Di Minin, A. European SMEs' engagement in open innovation When the important thing is to win and not just to participate, what should innovation policy do? Technol. Forecast. Soc. Chang. 2020, 152, 119843. [CrossRef]

34. Liu, B. The rise of frugal innovation and China. Sci. Technol. Prog. Policy 2015, 1, 7-11.

35. Bound, K.; Thornton, I.W. Our Frugal Future: Lessons from India's Innovation System; Nesta: London, UK, 2012.

36. Steinfeld, E.S.; Beltoft, T. Innovation lessons from China. MIT Sloan Manag. Rev. 2014, 55, 49.

37. Lampton, D.M. How China Is Ruled: Why its Getting Harder for Beijing to Govern. Foreign Aff. 2014, 93, 74-84.

38. Srinivas, S.; Kosonen, K.-J.; Viljamaa, K.; Nummi, J. Varieties of Innovation and Welfare Regimes: The Leap from R\&D Projects to the Development of City-Regions. Eur. Plan. Stud. 2008, 16, 1267-1291.

39. Chesbrough, H.W. A better way to innovate. Harv. Bus. Rev. 2003, 81, 12-13. [PubMed]

40. Prahalad, C.K. Bottom of the Pyramid as a Source of Breakthrough Innovations: BOP as Source of Innovations. J. Prod. Innov. Manag. 2012, 29, 6-12. [CrossRef] 
41. Chen, X. Analysis on the technical security of China's opening to the outside world from the perspective of market for technology. J. Hubei Adm. Inst. 2015, 2, 65-69.

42. Wei, H. The independent innovation of industrial clusters in China. Acad. J. Zhongzhou 2006, 3, 30-34.

43. Martinez, J.M.G.; de Castro-Pardo, M.; Pérez-Rodríguez, F.; Martín, J.M.M. Innovation and multi-level knowledge transfer using a multi-criteria decision making method for the planning of protected areas. J. Innov. Knowl. 2019, 4, 256-261. [CrossRef]

44. $\mathrm{Hu}, \mathrm{A}$. The 12th five-year plan for China's first camp. Outlook 2016, 36, 59-61.

(C) 2020 by the authors. Licensee MDPI, Basel, Switzerland. This article is an open access article distributed under the terms and conditions of the Creative Commons Attribution (CC BY) license (http://creativecommons.org/licenses/by/4.0/). 